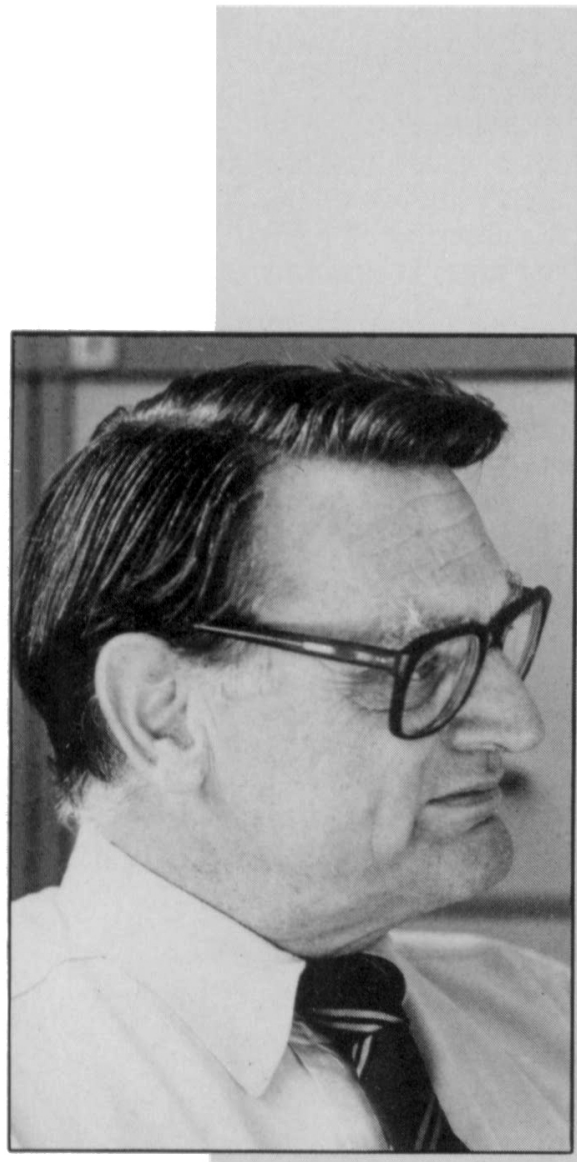

John B. Goodenough

\title{
Von Hippel Award Honors Prof. J.B. Goodenough
}

\section{In recognition of distinguished multidisciplinary research which has established the conceptual foundations of the science of solid state chemistry....}

Prof. John B. Goodenough has been named recipient of the 1989 Von Hippel Award. The Von Hippel Award, the premier award of the Materials Research Society, will be presented to Prof. Goodenough during a ceremony to be held the evening of November 29, 1989, in Boston in conjunction with the 1989 MRS Fall Meeting.

The Award honors his distinguished contributions to the field of solid state sciences, where his insights, ideas, knowledge and research have consistently drawn together the basic concepts of physics and chemistry in the conquest of wideranging fundamental topics. Through the years, his work can be said to have built the principal conceptual foundations of the science of solid state chemistry.

Prof. Goodenough has made pioneering contributions in many experimental fields, including such diverse topics as development of ferrite-core random access memories, high pressure studies of perovskites, and the analysis of lithium ion conductivity in spinels. He has addressed the electronic structure of complex materials, with concepts fundamental to chemical bonding. In the days before band structure calculations were routine, Prof. Goodenough succeeded in constructing, qualitatively, the band structures of most important semiconductors, oxides and metallic compounds. His 1963 book, Magnetism and the Chemical Bond, remains a classic reference in the field.

A similar intuitive approach underlies Prof. Goodenough's classic analysis of superexchange mechanisms and of metalinsulator transitions. His work on Mott localization in oxides is of fundamental significance. Prof. Goodenough's research on the electronic structure of transition metal compounds has covered magneticexchange interactions, localized treatment of outer electronic, martensitic phase transformation mechanisms, and structure of ferroelectrics and bronzes. He has studied the electronic structure of metals based on the interactions of Fermi surfaces with Brillouin-zone surfaces in reciprocal space.
He recently investigated the electron pairing mechanism in high $T_{c}$ supperconductor structures.

Prof. Goodenough has also made key contributions in materials for alternate energy technologies. These include solid electrolytes, solid-solution storage-cell electrodes, photoelectrolysis of water with sunlight, wavelength-selective coatings for solar collectors, zeolites for air conditioning with solar energy, catalytic electrodes, and heterogeneous catalysis.

Prof. Goodenough graduated from Yale University with a $\mathrm{BA}$ in mathematics in 1943, and obtained his $\mathrm{PhD}$ in physics at the University of Chicago in 1952 . His research in electronic materials (chemistry) continued at the Lincoln Laboratory until his move in 1976 to the University of Oxford as professor and head of the Inorganic Chemistry Laboratory. In 1986 he accepted the Virginia H. Cockrell Centennial Chair of Engineering at the University of Texas at Austin.

A member of the National Academy of Engineering, Goodenough has served extensively on government advisory boards and committees. He has also served in editorial positions for the Joumal of Applied Electrochemistry, Journal of Solid State Chemistry, International Series of Monographs on Chemistry (Oxford University Press), Solid State Ionics, Materials Research Bulletin, Structure and Bonding, and Superconductor Science and Technology. In 1980, he was honored with the title of Docteur Honoris Causa by the University of Bordeaux, and in 1980 he was awarded the Solid State Chemistry Prize of The Chemical Society (U.K.). As a recent tribute to his extraordinary record of achievement, the Joumal of Solid State Chemistry dedicated its January 1988 issue to him attesting to the esteem in which he is held by the world community of scientists and engineers.

The Von Hippel Award of the Materials Research Society honors Professor Goodenough's accomplishments for their depth and diversity, exemplifying the possibilities of interdisciplinary materials research. 


\section{The Von Hippel Award of The Materials Research Society}

The Von Hippel Award, the highest honor of the Society, acknowledges exceptional distinction in interdisciplinary materials research. All nominees must have outstanding scientific credentials, their work must have had a significant impact on materials research, and it must have exemplified an interdisciplinary approach. The Award is named in honor of its first recipient in 1976, Prof. Arthur von Hippel of the Massachusetts Institute of Technology. In addition to its prestige, the Award includes a cash prize and a mounted ruby laser crystal symbolizing the many-faceted nature of materials science.

Each year, nominations of distinguished scientists are received by the MRS Awards Committee and prepared for final evaluation by the Council of the Materials Research Society. The nominations traditionally present a most impressive standard of excellence, with truly difficult choices to be made among outstanding nominees.

\section{Previous Von Hippel Award Recipients}

1977

Arthur R. von Hippel

Emeritus Professor, Massachusetts

Institute of Technology

\section{8}

William O. Baker

Emeritus Chairman of the Board, Bell Laboratories

\section{9}

\section{David Turnbull}

Gordon McKay Professor of Applied Physics, Harvard University

\section{0}

W. Conyers Herring

Professor of Applied Physics,

Stanford University

\section{1}

James W. Mayer

Francis Norwood Bard Professor of Materials Science and Engineering, Cornell University

1982

Clarence M. Zener

Emeritus University Professor,

Carnegie Mellon University

\section{3}

Sir Peter B. Hirsch

Isaac Wolfson Professor of Metallurgy, University of Oxford

\section{4}

Walter L. Brown

Head of the Radiation Physics

Department, AT\&T Bell Laboratories

1985

John W. Cahn

Senior Fellow, Center of Materials

Science, National Bureau of

Standards

1986

Minko Balkanski

Professor of Physics and Director of the Solid State Physics Laboratory,

University of Pierre and Marie Curie

\section{7}

Sir Charles Frank

Professor Emeritus, University of Bristol

\section{8}

Jacques Friedel

Head of Physics Department, University of Paris

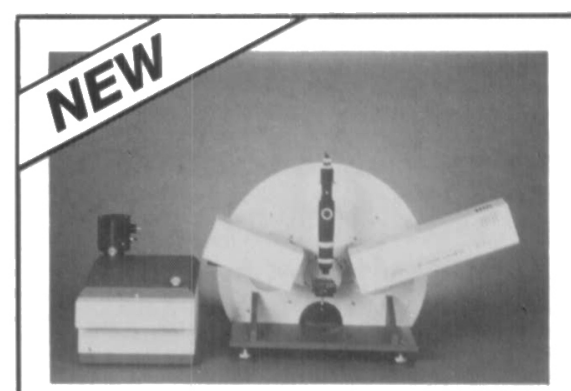

- Spectroscopic Ellipsometer

- Fully automated

- Wide spectral range

- With software for simulation and regression

- Ex - and in - situ configurations

The new 4th generation SOPRA Spectroscopic Ellipsometer (MULTILAYER OPTICAL SPECTROSCOPIC SCANNER - THE MOSS) is now available to help you to characterize your thin or thick films, analyze multilayers, map your wafers, fine tune your process. We can provide measurements from $230 \mathrm{~nm}$ to 1.1 microns at speeds up to 40 full spectra per second *!! The moss is based on an PC Computer System and can be demonstrated in your lab today.

Give us a call and we will be glad to arrange for you to see the moss in action.

" with the optional OMA detector system.

\section{SIMOX-multilayer-characterization}

The Tan (psi) and Cos (delta) spectra here below show the fit of the measured spectrum and the mode simulated spectrum after regression calculation.

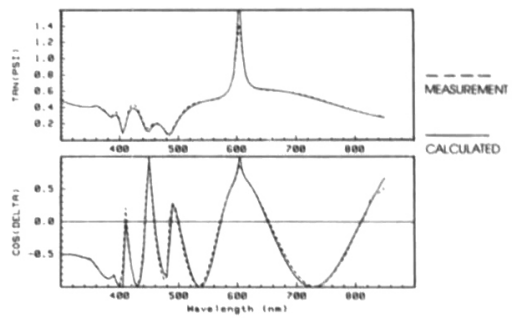

A cross comparison between Spectroscopic Ellipsometry and X-TEM gives very good agreement and show a better resolution of the multilayer structure.

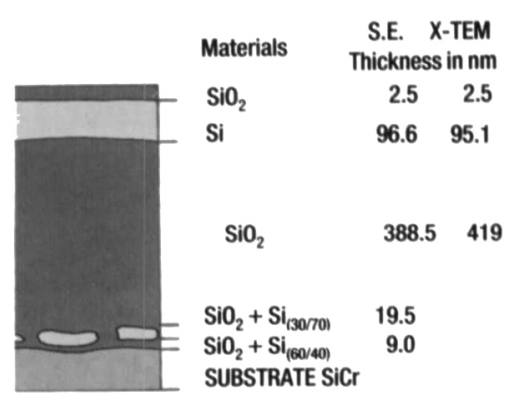

APPUICATIONS FOR RESEARCH AND CONTROL Physics of surface, Optical coating, Thin Films, Multilayer, Semiconductor, Implantation, Superlatttices, Solid State :

\section{एव्PA}

USA: ARIES/QEI - (508) 3699900

JAPAN: SEIKA Corp. - 032116814

GERMANY: L.0.T. - 06151/880610

UK: SPECTROLAB - 063524060

FRANCE : SOPRA SA

26/68 Rue Pierre-Joigneaux

F- 92270 Bois-Colombes

Tél. : 33-1 42420447

Fax : 33-1 42422934 